\title{
Revista Brasileira de Medicina de Família e Comunidade
}

\section{Ayurveda: an ancient science of holistic healing}

\author{
Shirley Telles MBBS, Ph.D. (Neurophysiology) ${ }^{1}$ \\ ${ }^{1}$ Patanjali Research Foundation (www.patanjaliresearchfoundation.com), Haridwar, India \\ E-mail: pyp.research@gmail.com
}

Ayurveda literally means the 'knowledge of living or of longevity', in Sanskrit. Ayurveda teachings elaborate how an individual can live in harmony with their surroundings. This includes pragmatic descriptions of the foods to be eaten, including where, when (according to the seasons and the time of the day) and how; as well as other practices, which includes yoga. In Ayurveda an emphasis is placed on three elemental humors (or doshas, in Sanskrit). These are usually described taking into account the five elements, viz., earth, water, fire, air and ether, which compose the whole Universe, including the human body. The doshas are vayu (air; comprised of wind and ether), pitta (bile; composed of fire and water), and kapha (phlegm; composed of water and earth). It is believed that the predominance of a particular dosha determines an individual's physical and mental characteristics. In this presentation a correlation would be made based on a study conducted on seven hundred healthy individuals, with the dosha dominant in each them and the occurrence of common complaints (e.g., an occasional headache). This may help in understanding which doshas make an individual particularly vulnerable to disorders of a specific organ or system. Apart from this the benefits of specific ayurveda practices will be presented based on scientific studies. This would include the use of polyherbal rejuvenating tonics to promote longevity and present disease as well as 'external therapies' such as 'shirodhara', which involves drop-by-drop application of medicated oils to the forehead for stress-reduction. Overall the presentation would aim at highlighting how Ayurveda blends specific practices with a holistic approach to promote positive health and prevent disease.

Key-words: Ayurveda. Holistic Healing. Herbs. 